\title{
TÉCNICAS DE SUBSTITUIÇÃO DE DNA MITOCONDRIAL PARA REDUZIR A TRANSMISSÃO DA SíNDROME DE LEIGH
}

\section{MITOCHONDRIAL DNA REPLACEMENT TECHNIQUES TO REDUCE LEIGH SYNDROME TRANSMISSION}

\author{
Angélica Godoy de Fraga, Virgínia Meneghini Lazzari²
}

\begin{abstract}
RESUMO
A Síndrome de Leigh (SL) é uma doença neuro-metabólica congênita, que faz parte do grupo das encefalopatias fatais, com progressão e morte dentro de 2 anos, em média. A SL é causada por mutações no DNA que causam alterações na geração de ATP celular pelas mitocôndrias. As mitocôndrias contêm seu próprio DNA (mtDNA) e, ao contrário do DNA nuclear, o mtDNA é herdado somente da mãe. Mulheres portadores de mutações causadoras da SL podem vivenciar experiências muito tristes ao tentarem realizar o sonho da maternidade. As técnicas de substituição de mtDNA mutado com mtDNA saudável de doadora, oferecem a essas mulheres a possibilidade de terem uma criança geneticamente relacionada sem a SL. O desenvolvimento e a aplicação clínica de terapias de substituição de mtDNA já são uma realidade, tendo o primeiro bebê gerado a partir da técnica nascido em 2016. Mas será que essas técnicas são seguras? Neste trabalho, revisamos a SL e algumas técnicas de substituição de mtDNA já aplicadas em humanos, que envolvem a transferência de pronúcleos de zigotos ou de fuso acromático de oócitos. Concluímos que, apesar dos resultados promissores, ainda é cedo para assegurar a aplicabilidade clínica de técnicas de substituição de mtDNA em seres humanos.
\end{abstract}

Palavras-chave: Fertilização in vitro; taxa de mutação; doação de oócitos; desenvolvimento embrionário; zigoto; diagnóstico pré-implantação; transferência de pronúcleos; transferência de fuso acromático

\begin{abstract}
Leigh syndrome (SL) is a congenital neurometabolic disease included in the group of fatal encephalopathies, with progression and death within 2 years on average. SL is caused by mutations in the DNA that cause changes in the generation of cellular ATP by mitochondria. Mitochondria contain their own DNA (mtDNA) and, unlike nuclear DNA, mtDNA is inherited only from the mother. Women with SL mutations may experience mournful situations when attempting to fulfill the dream of motherhood. Techniques for replacing mutant mtDNA with healthy donor mtDNA provide these women with the possibility of having a genetically related child without SL. The development and clinical application of mtDNA replacement therapies is a reality, and the first baby generated using the technique was born in 2016. However, are these techniques safe? In this article, we review SL and some mtDNA replacement techniques that have been used in humans, which involve zygote pronuclear transfer or oocyte spindle transfer. We conclude that, despite the promising results, it is too early to ensure that mtDNA replacement techniques are clinically applicable to humans.
\end{abstract}

Keywords: In vitro fertilization; mutation rate; oocyte donation; embryonic development; zygote; preimplantation diagnosis; pronuclear transfer; spindle transfer

\section{INTRODUÇÃO}

As células eucarióticas contêm dois tipos de DNA: o DNA nuclear (nDNA), que é organizado em cromossomos e está localizado no núcleo celular; e o DNA mitocondrial (mtDNA), presente dentro das mitocôndrias, que consiste
Clin Biomed Res. 2021;41(1):65-74

1 Escola de Ciências da Saúde, Centro Universitário Ritter dos Reis. Porto Alegre, RS, Brasil.

\footnotetext{
2 Centro de Ciências Biológicas, Departamento de Ciências Morfológicas, Universidade Federal de Santa Catarina (UFSC). Florianópolis, SC, Brasil.

Autor correspondente: Virgínia Meneghini Lazzari vivimeneghini@gmail.com Centro de Ciências Biológicas, Departamento de Ciências Morfológicas, Universidade Federal de Santa Catarina (UFSC). Rua Roberto Sampaio Gonzaga, s/n. 88040-900, Florianópolis, SC, Brasil.
} 
em moléculas circulares pequenas. Enquanto o nDNA é herdado de ambos os pais, o mtDNA é herdado exclusivamente da mãe ${ }^{1}$. O pequeno número de mitocôndrias introduzidas pelo espermatozoide é alvo de destruição por um mecanismo autofágico conservador conhecido como mitófago. Assim, o mtDNA (>100.000 cópias) presente no oócito, constitui a população fundadora das mitocôndrias em todos os tipos de células do embrião resultante ${ }^{2}$.

A Síndrome de Leigh (SL) é uma doença neurometabólica congênita, que faz parte do grupo das encefalopatias fatais. É causada por mutações no mtDNA ou no nDNA que causam defeitos na síntese de Adenosina Trifosfato (ATP) pelas mitocôndrias ${ }^{3}$. Pelo menos uma a cada 5000 pessoas na população em geral possui uma mutação no mtDNA, podendo causar ou não disfunções mitocondriais e doenças hereditárias maternas. Nestes casos, os sintomas relacionados à $S L$ dependem do nível de carga da mutação do mtDNA, sendo que a probabilidade de ter sintomas graves e fenótipo patológico é baixa 4 .

Embora tenham como principal função a produção de energia celular, as mitocôndrias desempenham outros papeis importantes, tais como sinalizadores de cálcio, regulação do metabolismo celular, desenvolvimento embrionário e morte celular programada 5 . Prever o risco dos filhos de mulheres portadoras de mutações de mtDNA manifestarem uma doença relacionada é complicado pois depende da quantidade de mtDNA mutado que será transmitido para cada oócito ${ }^{6} \mathrm{e}$, no caso de mulheres com heteroplasmia (com mitocôndrias com mtDNA selvagem e mutado), os oócitos apresentam cargas mutantes amplamente variadas ${ }^{7}$. Além disso, embora a patogenicidade seja geralmente proporcional à quantidade de mtDNA mutado para selvagem, a gravidade da doença para uma dada carga de mutação pode variar entre indivíduos ${ }^{7}$. Assim, mulheres portadoras de mutações no mtDNA podem sofrer uma série de abortos e, caso engravidem, a chance da prole de apresentar a SL é imprevisível.

As opções clínicas atuais para prevenir a transmissão de mutações do mtDNA ao embrião são limitadas. Um casal pode adotar uma criança, usar oócitos de doadora ou usar a técnica de diagnóstico genético pré-implantacional (PGD) para identificar o embrião acometido pela doença. O PGD é geralmente utilizado para detectar mutações em nDNA, embora possa também determinar a carga mutacional de $\mathrm{mtDNA}$ e reduzir o risco de transferência de um embrião portador da doença em mulheres com baixas cargas de mutação. Mesmo assim, através de PGD, não há uma maneira confiável de pré-selecionar embriões para a maioria dos casos de mutação de mtDNA, particularmente para uma mulher com um alto nível de heteroplasmia ${ }^{4}$. Além disso, o PGD não é útil para as mulheres que são homoplásmicas para mutações patogênicas ${ }^{6}$.
Em fevereiro de 2015, o Parlamento do Reino Unido votou a favor da aplicação clínica de procedimentos de fertilização in vitro envolvendo doação mitocondrial e se tornou o primeiro lugar no mundo a legalizar tecnologias transferência de citoplasma em linhagem germinativa ${ }^{8}$. Em abril de 2016, o primeiro bebê desenvolvido a partir da técnica de transferência de citoplasma nasceu no México ${ }^{9}$. A notícia foi veiculada mundialmente pela mídia como o nascimento do bebê de três pais (Three-parent baby). Apesar de a técnica ter sido rapidamente aplicada na rotina clínica, podem ocorrer incompatibilidades entre os genomas mitocondrial e nuclear resultantes do processo e a técnica é recente e não bem discutido ainda ${ }^{10}$. Assim, este trabalho objetiva revisar os sinais e sintomas clássicos e as principais alterações moleculares da SL, bem como revisa as técnicas de transferência de DNA nuclear utilizadas em reprodução assistida que objetivam reduzir a chance de transmissão da SL e de outras síndromes causadas por mutações no mtDNA para os filhos de mães com a síndrome.

\section{MÉTODOS}

Trata-se de uma revisão narrativa da literatura. A busca de artigos para a elaboração deste estudo foi desenvolvida a partir de pesquisas nas bases de dados PubMed e Scielo, onde a busca foi composta de dois domínios básicos, um deles focando na técnica de transferência de citoplasma e o outro domínio mais focado na SL em si. A realização da pesquisa em duas etapas foi necessária, pois não foram encontrados artigos que revisassem tanto a SL quanto as técnicas de reprodução assistida utilizadas para o manejo de embriões com a síndrome.

Para o primeiro domínio de pesquisa, a busca focou em técnicas de transferência de DNA mitocondrial. A pesquisa foi construída como Leigh Syndrome Assisted Reproduction Mitochondrial DNA: ("leigh disease" [MeSH Terms] OR ("leigh" [All Fields] AND "disease" [All Fields]) OR "leigh disease" [All Fields] OR ("leigh" [All Fields] AND "syndrome" [All Fields]) OR "leigh syndrome" [All Fields]) AND assisted [All Fields] AND ("reproduction" [MeSH Terms] OR "reproduction" [All Fields]) AND ("dna, mitochondrial" [MeSH Terms] OR ("dna" [All Fields] AND "mitochondrial" [All Fields]) OR "mitochondrial dna" [All Fields] OR ("mitochondrial" [All Fields] AND "dna" [All Fields]).

Como os artigos encontrados no primeiro domínio de pesquisa não detalhavam a SL, optou-se por uma segunda frente de pesquisas relacionando a SL e mutações mitocondriais. Nesse contexto, adotou-se como método de pesquisa a construção Leigh Syndrome Mitochondrial DNA: "leigh syndrome" [All Fields] AND ("dna, mitochondrial" [MeSH Terms] OR "mitochondrial dna" [All Fields]). 
Após a busca inicial, os artigos tiveram seus títulos e resumos revisados e separadas quando consideradas relevantes para o assunto. A segunda etapa de análise foi realizada a partir da avaliação dos textos completos, com posterior leitura interpretativa e redação do artigo.

\section{RESULTADOS}

Como resultado inicial da pesquisa, foram identificados 77 artigos relacionados a técnicas de transferência de DNA mitocondrial e 1586 artigos relacionados à SL (Figura 1). Após a leitura dos títulos e resumos, foram selecionados artigos que se encaixavam no tema do estudo, para uma leitura mais detalhada. As buscas foram filtradas de forma que compreendessem apenas estudos em inglês, publicados até julho/2020. Os critérios de inclusão foram: artigos de pesquisa e revisões da literatura sobre técnicas de transferência mtDNA e SL em humanos. Artigos sobre estudos em animais e relatos de casos foram excluídos, mesmo que abordassem a temática pesquisada.

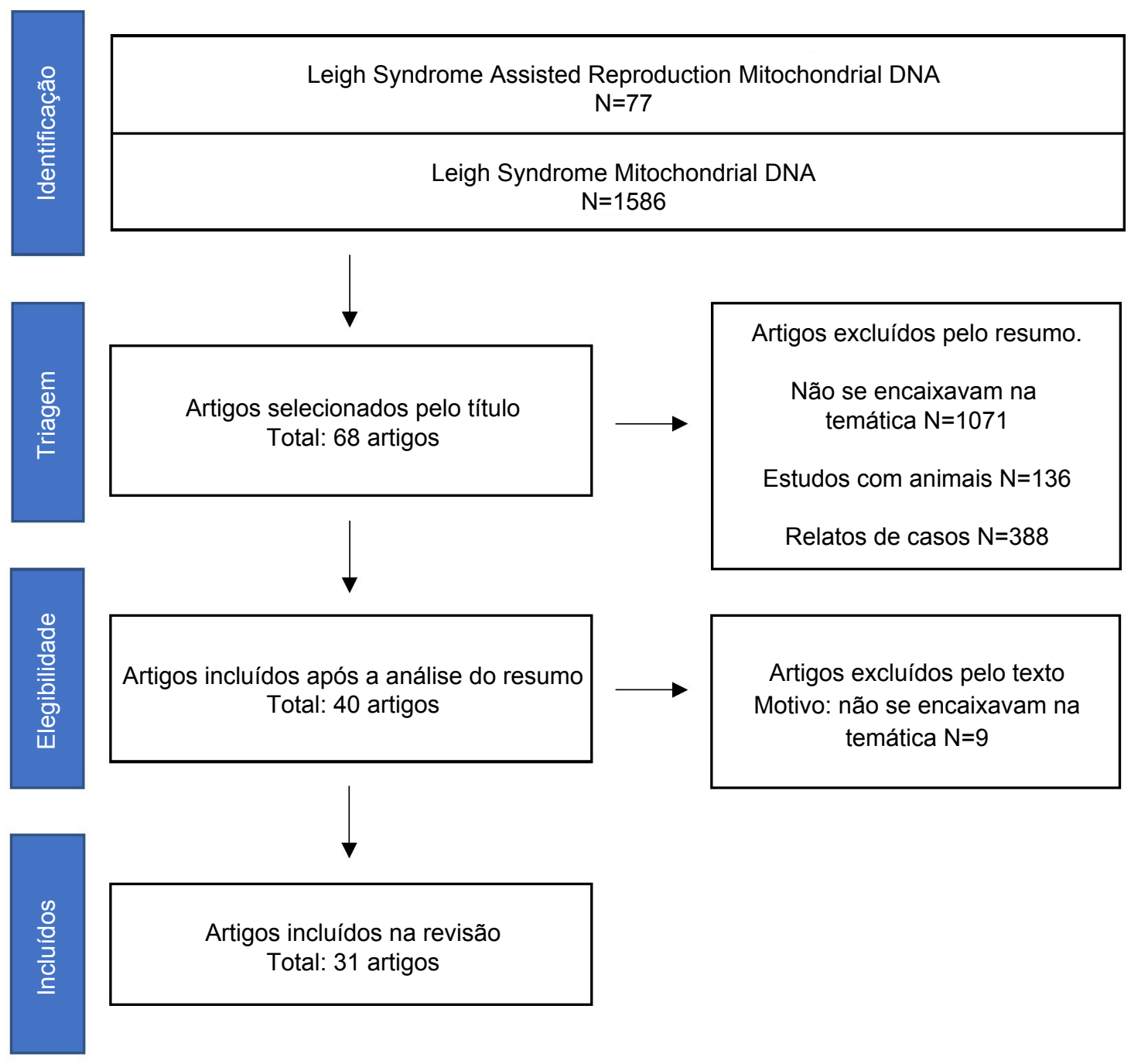

Figura 1: Fluxograma de seleção dos estudos para o desfecho definido pelos autores.

Os principais motivos para exclusão dos artigos foram o não enquadramento destes na temática do estudo. No primeiro domínio de pesquisa (técnicas de transferência de mtDNA) a maioria dos artigos excluídos abordava aspectos éticos e morais da técnica ou sobre a utilização da técnica para oócitos de pacientes com idade materna avançada para melhorar o desenvolvimento embrionário, fugindo da temática proposta por este trabalho.

$\mathrm{Na}$ pesquisa sobre a SL, selecionamos principalmente artigos de revisão e séries de casos que fizessem uma abordagem mais ampla da doença, 
trazendo informações sobre sintomas, tratamentos e fisiopatologia. Os artigos excluídos abordavam patologias semelhantes à SL ou então apesar de abordar a SL, eram relatos de casos ou possuíam uma temática limitada a um aspecto específico da síndrome, como por exemplo: artigos que descreviam uma mutação de nDNA ou de mtDNA, artigos sobre exames diagnósticos de imagem, condutas médicas em casos em tratamentos, estudos de achados post-mortem.

Após a seleção dos artigos baseada na leitura dos títulos e resumos, uma leitura mais detalhista do conteúdo dos trabalhos foi feita. A partir desta análise foram selecionados os artigos utilizados para a construção deste manuscrito (Figura 1). Entre os 31 artigos selecionados para a composição dessa revisão, 7 artigos versavam sobre mutações no DNA mitocondrial, 9 artigos tratavam sobre a SL e 15 artigos relatavam avanços e técnicas de substituição de DNA mitocondrial.

\section{DISCUSSÃO}

\section{Mutações no DNA mitocondrial}

As mitocôndrias são organelas encontradas em todas as células nucleadas. Elas têm uma infinidade de funções, mas é justo dizer que o que as distingue é o seu papel na produção energética, pois geram mais de $90 \%$ do ATP de uma célula ${ }^{11}$. As mitocôndrias contêm seu próprio DNA, e ao contrário do nDNA, os mtDNAs são herdados somente da mãe e estão presentes em múltiplas cópias por célula, variando de acordo com a necessidade energética de cada tecido em particular ${ }^{12}$.

O mtDNAé constituído como um círculo compacto de cadeia dupla com 16.569 pares de bases. Ele contém 37 genes, 13 dos quais codificam subunidades da fosforilação oxidativa, 22 genes de RNA transportador e 2 genes de RNA ribossômico; não contém íntrons, mas apresenta vários genes sobrepostos e códons de terminação incompleta ${ }^{8}$. Evolutivamente, genes que codificam proteínas mitocondriais foram incorporados no nDNAe alguns poucos genes foram mantidos no $\mathrm{mtDNA}^{11}$, assim, embora poucas proteínas sejam codificadas pelo genoma mitocondrial, mais de mil proteínas mitocondriais são codificadas pelo genoma nuclear ${ }^{13}$. Essa interrelação entre a transcrição do nDNA e do mtDNA é essencial para o correto funcionamento da mitocôndria.

As mutações do mtDNA são encontradas em $0,5 \%$ da população, segundo dados prévios ${ }^{14}$. Altos níveis de mtDNA mutado estão associados a doenças graves que frequentemente afetam o sistema nervoso. Atualmente, não há tratamentos para essas doenças, assim, prevenir a transmissão genética das mutações é a prioridade nesses casos ${ }^{15}$. A grande variação da quantidade de mtDNA mutado dentro das células acaba mascarando a real frequência de mutações potencialmente patogênicas na população. Embora a prevalência das doenças mitocondriais não seja tão grande, a frequência populacional das dez mutações de mtDNA patogênicas mais comuns é muito maior - aproximadamente uma em cada 200 pessoas - sugerindo que muitos indivíduos normais possuem níveis baixos de mutações de mtDNA potencialmente nocivas ${ }^{12}$.

As mutações no mtDNA podem reduzir a produção de ATP mitocondrial, afetando particularmente os órgãos com alta demanda energética, tais como o cérebro, músculo e coração. As cópias mutadas de mtDNA presentes no oócito são transmitidas ao embrião. Mutações podem estar presentes em todas as cópias do mtDNA (homoplasmia) ou apenas uma fração de cópias (heteroplasmia) (Figura 2) e a gravidade do quadro clínico os sintomas são determinados pela razão entre mutado e selvagem ${ }^{2}$.

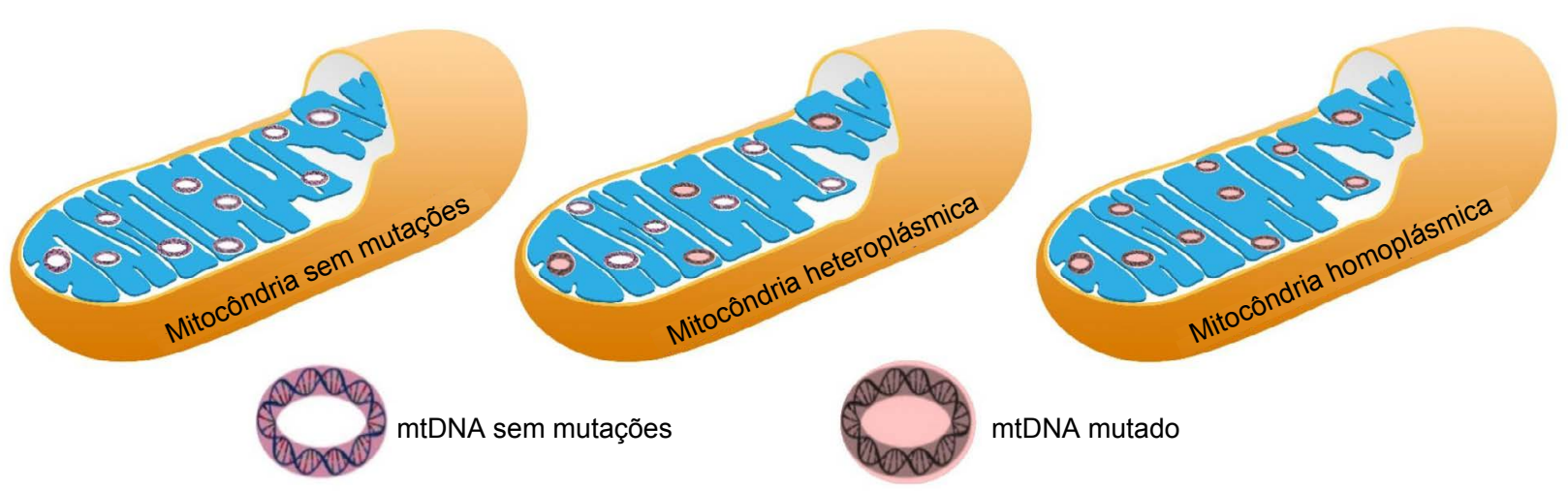

Figura 2: DNA mitocondrial. 
Em mulheres com doença homoplásmica, todo o complemento do mtDNA carrega a mutação, portanto, todos os oócitos são afetados. Por outro lado, o oócitos de mulheres com mtDNA heteroplásmico contêm cargas variáveis de mutação do mtDNA. Pensa-se que isso se deva a um fenômeno conhecido como gargalo genético do mtDNA, que envolve um declínio dramático no número de cópias de mtDNA durante a gametogênese feminina, originando um efeito de amostragem estatística o que resulta em acentuada variação no nível de heteroplasmia entre oócitos ${ }^{7,16}$. Como consequência, a transmissão de doença de mtDNA de uma mulher heteroplásmica para seus filhos é imprevisível ${ }^{2}$.

Através da utilização técnicas padrão de sequenciamento, foram identificadas mutações patogênicas associadas a várias síndromes causadas pelo mau funcionamento mitocondrial. A mutação causadora da síndrome tanto pode estar localizada no nDNA em um gene codificador de proteína mitocondrial quanto no mtDNA. Segundo Schon et al. ${ }^{12}$, as principais doenças mitocondriais primárias relacionadas ao DNA são: Neuropatia óptica hereditária de Leber (LHON), Síndrome de Leigh (SL), Encefalomiopatia mitocondrial, acidose láctica e episódios semelhantes a AVC (MELAS) e Epilepsia do mioclonia e fibras vermelhas irregulares (MERRF). Este estudo foca na SL por ser a principal apresentação pediátrica fatal causada por mutações no mtDNA.

\section{Síndrome de Leigh}

ASLé uma síndrome neuro-metabólica congênita, que faz parte do grupo das encefalopatias mitocondriais. É causada por alteração no metabolismo energético, sendo a principal causa defeito na fosforilação oxidativa e geração de ATP celular. Aidade de início desta doença é variada e ocorre em geral nos primeiros dois anos de vida, podendo ocorrer manifestações no adulto jovem. A evolução em geral é insidiosa e progressiva ${ }^{17}$.

ASL é a apresentação pediátrica mais comum da doença mitocondrial. Este distúrbio neurodegenerativo é geneticamente heterogêneo, e até o momento foram identificadas mutações patogênicas em mais 75 genes, codificados tanto pelo genoma mitocondrial quanto pelo nuclear ${ }^{18}$. Os genes associados à doença codificam proteínas das vias de geração de energia mitocondrial, subunidades codificadoras da fosforilação oxidativa e fatores de montagem associados, enzimas envolvidas na biossíntese de ubiquinona e no complexo da piruvato desidrogenase. Portanto, a SL poderia ser considerada uma manifestação clínica e neuropatológica de uma ampla gama de distúrbios monogênicos da geração de energia ${ }^{18,19}$. Sobre a frequência das mutações encontradas, a maioria dos pacientes apresentam mutação no nDNA relacionado a genes mitocondriais, enquanto $25 \%$ dos casos são causados por mutações no mtDNA ${ }^{20}$. No mtDNA, mutações em 15 dos 37 genes foram descritos como causadores de SL, a maioria dos quais codifica subunidades do complexo I ou V (Tabela 1$)^{21}$.

Tabela 1: Características e tratamentos da Síndrome de Leigh.

\begin{tabular}{|c|c|c|}
\hline & Síndrome de Leigh & Referências bibliográficas \\
\hline $\begin{array}{l}\text { Principais mutações no } \\
\text { mtDNA associadas à SL }\end{array}$ & $\begin{array}{l}\text { Complexo I: MT-ND1, MT-ND2, MT-ND3, MT-ND4, MT- } \\
\text { ND5, MT-ND6 } \\
\text { Complexo IV: MT-CO3 } \\
\text { Complexo V: MT-ATP6 } \\
\text { Tradução Mitocondrial: MT-TI, MT-TK, MT-TL1, MT-TV, } \\
\text { MT-TW }\end{array}$ & Lake et al. ${ }^{18}$ \\
\hline Sintomas mais frequentes & $\begin{array}{l}\text { Atraso ou regressão psicomotora } \\
\text { Hipotonia } \\
\text { Distonia } \\
\text { Ataxia } \\
\text { Anormalidades dos movimentos oculares } \\
\text { Paralisia bulbar } \\
\text { Paralisia piramidal } \\
\text { Convulsões } \\
\text { Disfunção da deglutição } \\
\text { Termorregulação anormal } \\
\text { Distúrbios respiratórios }\end{array}$ & Baertling et al. ${ }^{3}$ \\
\hline $\begin{array}{l}\text { Principais manifestações } \\
\text { bioquímicas e patológicas }\end{array}$ & $\begin{array}{l}\text { Hiperlacticacidemia no sangue ou líquido } \\
\text { cefalorraquidiano } \\
\text { Ácidos orgânicos elevados na urina } \\
\text { Gliose }\end{array}$ & Lake et al. ${ }^{19} \mathrm{e}$ Wei et al. ${ }^{22}$ \\
\hline
\end{tabular}


Fraga et al.

Tabela 1: Continuação

\begin{tabular}{|c|c|c|}
\hline & Síndrome de Leigh & Referências bibliográficas \\
\hline $\begin{array}{l}\text { Principais manifestações } \\
\text { bioquímicas e patológicas }\end{array}$ & $\begin{array}{l}\text { Desmielinização } \\
\text { Hipertrofia da vasculatura cerebral } \\
\text { Vacuolização de processos astrocitários e neuronais } \\
\text { (característica histológica de neurodegeneração) } \\
\text { Preservação neuronal relativa } \\
\text { Lesões simétricas bilaterais nos gânglios da base } \\
\text { Lesões simétricas bilaterais no tronco cerebral }\end{array}$ & Lake et al. ${ }^{19} \mathrm{e}$ Wei et al. ${ }^{22}$ \\
\hline Tratamentos paliativos & $\begin{array}{l}\text { Coenzima Q10 (ubiquitinona) serve como transportador } \\
\text { de elétrons do complexo II para o complexo III } \\
\text { Piruvato: restaura a função gliceraldeído-3-fosfato } \\
\text { desidrogenase (GAPDH) } \\
\text { Dicloroacetato: regula o metabolismo do piruvato e } \\
\text { estimula o ciclo de Krebs } \\
\text { Vitaminas C, E, B1 e B2 (administradas separadamente ou } \\
\text { em coquetel): auxiliam no funcionamento do ciclo de Krebs }\end{array}$ & Wei et al. ${ }^{22} \mathrm{e}$ Chen et al. ${ }^{23}$ \\
\hline
\end{tabular}

O início dos sinais e sintomas (Tabela 1) ocorre de forma subaguda ou abrupta, podendo em alguns casos ser precipitado por episódios febris; os pacientes geralmente apresentam regressão das habilidades mentais e motoras levando à incapacidade e rápida progressão para a morte, muitas vezes devido a convulsões e insuficiência respiratória ${ }^{4}$. No geral, o curso da doença é gradualmente misturado com exacerbações agudas intercorrentes seguintes infecções. O início da doença normalmente ocorre entre 3 e 12 meses de idade, com progressão da doença e morte dentro de 2 anos $^{24}$. A SL de início tardio, isto é, o aparecimento após os 2 anos de idade é considerada rara; nestes casos os sintomas mais comuns são a alta prevalência de ataxia e paralisia espástica ${ }^{22}$.

Embora os distúrbios da fosforilação oxidativa mitocondrial sejam bastante variados, eles apresentam características bioquímicas típicas. Uma característica óbvia é a deficiência da cadeia respiratória, que normalmente se manifesta como função enzimática reduzida em um ou mais complexos da cadeia, com uma redução concomitante na síntese de ATP ${ }^{12}$. Entre todas as alterações bioquímicas relatadas para a SL, a deficiência do complexo I na via da fosforilação oxidativa é a apresentação bioquímica mais comum ${ }^{18,23}$. As manifestações da doença são consequência da falta de ATP e podem ocorrer em um único tecido ou órgão afetado, mas um envolvimento multissistêmico ou de vários órgãos é mais comum e tem os maiores efeitos sobre órgãos com alta demanda de energia (Tabela 1$)^{8}$.

O diagnóstico da síndrome baseia-se exames de imagem que detectam lesões simétricas em uma ou mais áreas do sistema nervoso central, incluindo os gânglios basais, diencéfalo, tronco encefálico, cerebelo e medula espinhal ${ }^{24}$. Exames bioquímicos são utilizados para confirmar os exames de imagem
(Tabela 1). O aumento dos níveis de lactato no sangue e líquor e a relação lactato/piruvato também podem ser usados como parâmetros para avaliação ${ }^{22}$.

Por se tratar de uma doença sem cura, o tratamento consiste em medidas paliativas para amenizar os sintomas dos pacientes (Tabela 1). Geralmente são utilizadas medicações anticonvulsivantes, controle da disfunção endócrina, controle dietético e procedimentos cirúrgicos, caso necessário. A remoção de metabólitos nocivos objetiva o combate da acidose lática. Exercícios aeróbicos aumentam a tolerância a outros exercícios. O acompanhamento multidisciplinar, com a pediatria, neurologia, cardiologia, fisioterapia, oftalmologia e outras áreas, para a avaliação da gravidade das alterações e sua evolução são de suma importância, a fim de averiguar se a doença está sob controle, já que seu curso é progressivo ${ }^{3,23}$.

\section{Técnicas de substituição mitocondrial para pacientes com Síndrome de Leigh}

Pacientes portadores de mutações relacionadas à SL podem procurar clínicas de reprodução assistida para evitar a transmissão da doença para os filhos. Algumas clínicas oferecem diagnóstico genético pré-implantacional (PGD) para medir o nível de heteroplasmia de mtDNA em embriões desenvolvidos in vitro. Essa conduta não é um padrão, pois devido ao padrão de multiplicação de mitocôndrias durante o desenvolvimento embrionário, o PGD não apresenta resultados confiáveis quanto à prevenção transmissão de mutação, uma vez que a taxa de mtDNA para um embrião se desenvolver sem manifestar a doença não é conhecido ${ }^{10}$.

O PGD pode ser utilizado para identificar embriões com baixas cargas de mutação, mas não é efetivo para mulheres com mutações de mtDNA homoplásmicas, já que todos os seus filhos serão 
afetados, ou para mulheres com cargas de mutação de mtDNA heteroplásmicas próximas ao limiar da doença ${ }^{25}$. Para abordar esta questão, pesquisas recentes se concentraram no desenvolvimento de técnicas para reduzir o risco de transmissão de doenças de mtDNA transplantando o genoma nuclear entre os oócitos antes ou depois da fertilização com o objetivo de desacoplar a herança de nDNA do mtDNA. Em princípio, isso permitiria que as mulheres que carregam mutações de mtDNA tenham uma criança geneticamente relacionada, reduzindo muito o risco de transmissão de mutações de mtDNA ${ }^{2}$.

Estas técnicas são conhecidas como técnicas de substituição mitocondrial e foram autorizados para uso clínico no Reino Unido em outubro de 2015. Em julho de 2016, a Autoridade de Fertilização e Embriologia Humana (HFEA) anunciou que a segurança e a eficácia das técnicas deviam ser confirmadas antes de serem utilizadas. Para isso, um grupo de cientistas foi convocado e a revisão foi publicada em novembro de 2016, recomendando que "em circunstâncias específicas, as técnicas de substituição mitocondrial sejam adotadas com cautela na prática clínica em que a herança da doença provavelmente causará morte ou doença grave e onde não há alternativas aceitáveis". Após, em 15 de dezembro de 2016, a HFEA aprovou o uso da doação mitocondrial em determinados casos específicos. As clínicas que desejam oferecer essas técnicas aos pacientes poderiam se inscreverem na HFEA para obter permissão para fazê-lo após a avaliação de cada caso ${ }^{14}$.

As técnicas de substituição de mtDNA visam erradicar o mtDNA do indivíduo portador da mutação. Isso significa que os embriões não apresentariam mtDNA mutado. No entanto, há sempre algum nível de transição, o que pode significar que os níveis de mtDNA mutantes aumentam durante o desenvolvimento subsequente - um fenômeno conhecido como "instabilidade genética", "deriva genética" ou "reversão" - fazendo com que a doença reapareça em gerações posteriores ${ }^{6}$, por isso seria prudente que a técnica fosse utilizada somente em embriões do sexo masculino, que não irão contribuir com mitocôndrias para as gerações futuras ${ }^{26}$. Um estudo de Samuels et al. ${ }^{15}$ calculou que, para um limiar clínico de $60 \%$, a redução do mtDNA mutante transferido para menos de $5 \%$ erradicaria a doença para sempre na linhagem, enquanto que se essa taxa for maior que $5 \%$, a probabilidade de reaparecer nas gerações subsequentes é alta, por isso é importante limitar a transmissão de mtDNA mutante a níveis inferiores a 3\%. Estes baixos níveis já foram alcançados com as técnicas, no entanto, estes são cálculos probabilísticos, portanto, nenhuma reivindicação pode ser feita com certeza completa a este respeito.

O genoma nuclear pode ser transferido dos oócitos ou zigotos usando técnicas como transferência de pronucleos (TPN), transferência do fuso materno (TFM), transferência do corpúsculo polar (TCP) e transferência de vesícula germinativa (TVG), sendo as duas primeiras (TPN e TFM) as técnicas aplicadas para o desenvolvimento de embriões humanos para casos de mutações no mtDNA ${ }^{10,27}$.

\section{Transferência de pronúcleos (TPN)}

Durante o processo de fertilização in vitro, oócitos maduros, em metáfase II, com a presença de um corpúsculo polar (CP), são fertilizados por um espermatozoide. Logo após a fertilização, a segunda meiose do oócito é completada, os genomas haploides do oócito e do espermatozoide são então embalados separadamente em pronúcleos ${ }^{2}$ e o zigoto apresenta dois CPs. Neste estágio de desenvolvimento é realizada a primeira técnica de transplante, a TPN. A TPN (Figura 3) consiste em realizar a fertilização in vitro utilizando os oócitos da mulher afetada - cujas mitocôndrias contêm mutações no mtDNA - e os espermatozoides do futuro pai. Posteriormente realiza-se a extração dos pronúcleos, deixando para trás a maioria das mitocôndrias mutadas. Estes pronúcleos são transferidos para um zigoto de doador enucleado com mitocôndrias saudáveis. Eles devem ser transferidos para um zigoto enucleado, não um oócito, uma vez que o estado de desenvolvimento deve ser o mesmo. O zigoto híbrido é então desenvolvido in vitro até atingir um estado apropriado para transferência para o útero ${ }^{14,27,28}$.

De acordo com um estudo de Hyslop et al. ${ }^{6}$, após utilização da técnica, o acúmulo de mtDNA foi reduzido para menos de $2 \%$ nos blastocistos de TPN. A importância desta redução para os níveis mais baixos possíveis é devido a um aumento progressivo da heteroplasmia numa linha de células estaminais derivada de um blastocisto de TPN com $4 \%$ de mtDNA. Sabe-se, portanto, que a transferência tem potencial para reduzir o risco de doença, mas pode não garantir a prevenção para gerações futuras. A TPN logo após a conclusão da meiose resulta em uma sobrevivência melhorada. A otimização dos procedimentos de enucleação do embrião promove o desenvolvimento de blastocistos de boa qualidade, cuja expressão gênica e incidência de aneuploidia não diferiram dos controles. Dados os baixos níveis de transferência de mtDNA usando procedimentos otimizados, os autores acreditam que a TPN tem o potencial de reduzir o risco de doença do mtDNA. 


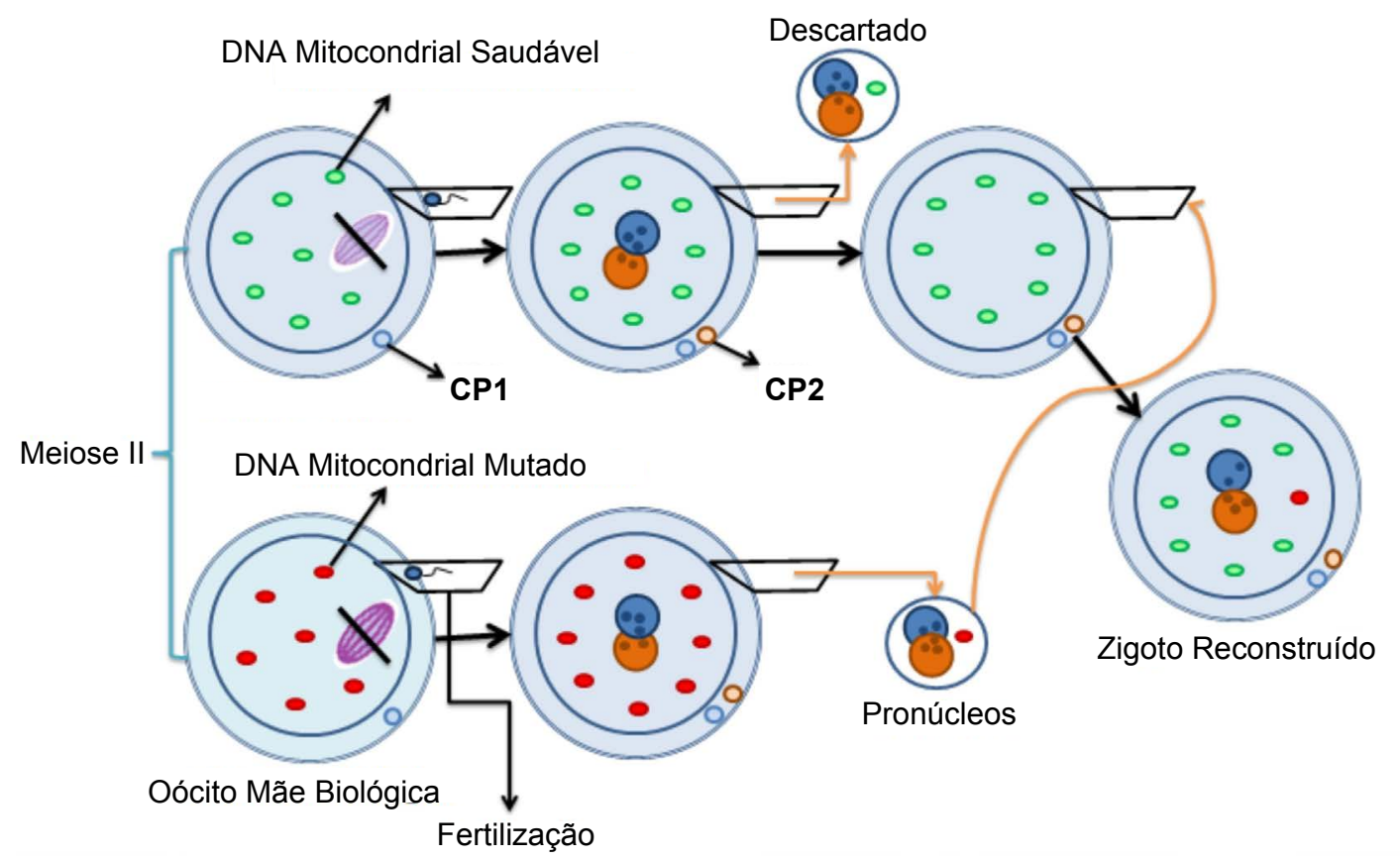

Figura 3: Transferência de pronúcleos.

\section{Transferência de fuso materno (TFM)}

A segunda técnica de transplante é a transferência de fuso materno (TFM), que consiste em extrair os cromossomos do oócito da mãe- cujo mtDNA tem mutação - na metáfase II (oócito com $1 \mathrm{CP}$ ) e depois transferi-los para um oócito de doadora saudável, no qual os cromossomos foram removidos
(Figura 4) na mesma fase de maturação. O oócito híbrido é fertilizado in vitro e depois transferido para o útero da mãe ${ }^{14,27,29}$. A TFM foi testada em oócitos humanos pela primeira vez por Tachibana et al. ${ }^{30}$ que confirmaram a viabilidade da técnica. Em 2016 a técnica começou a ser aplicada para pacientes com mutações patogênicas no mtDNA ${ }^{31}$, também demonstrando viabilidade da técnica in vitro.

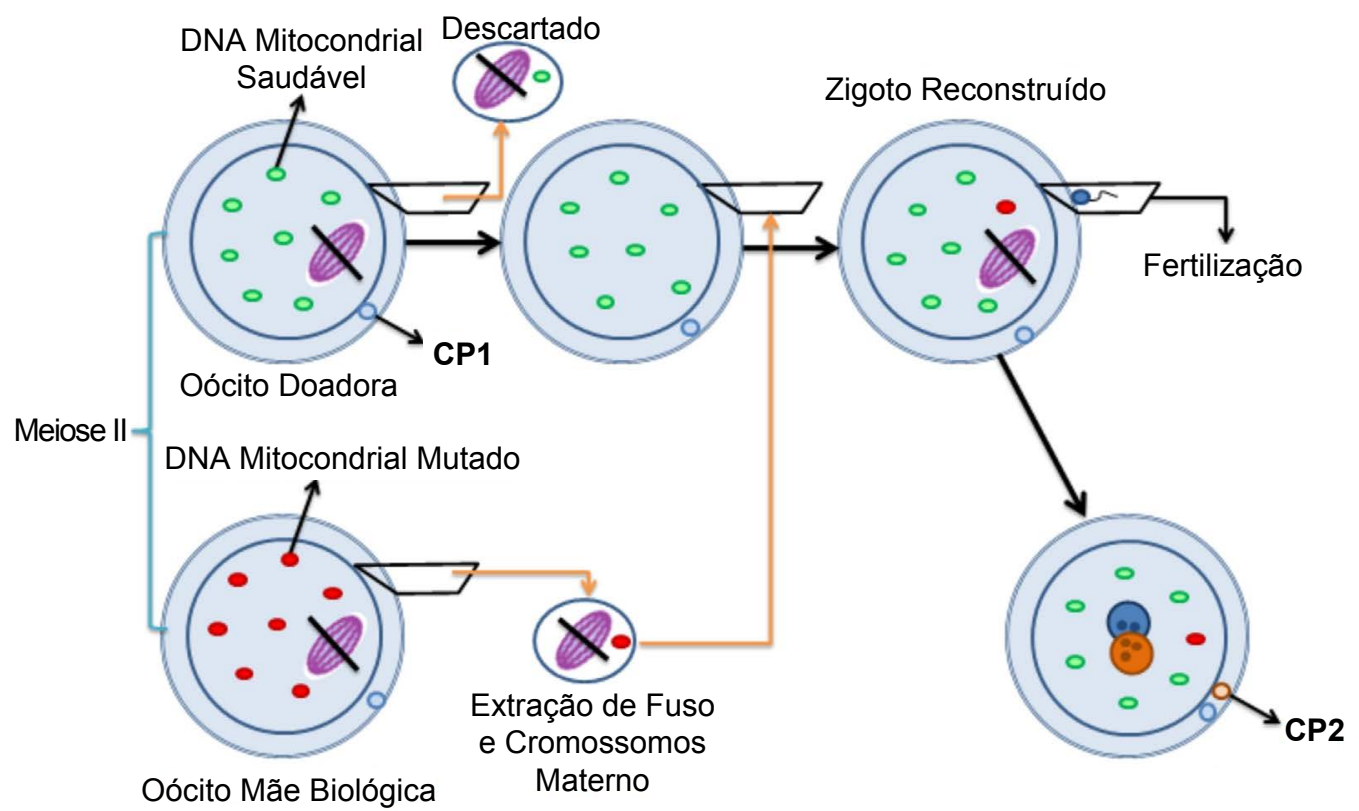

Figura 4: Transferência de fuso materno. 
Apesar de a notícia do primeiro nascimento a partir da técnica ter sido veiculada na mídia mundial em 2016, o trabalho de Zhang et al. ${ }^{4}$ sobre a técnica utilizada foi publicado apenas em 2017. Assim, o primeiro humano nascido a partir da técnica de substituição de mtDNA foi desenvolvido a partir da técnica de TFM. No caso detalhado, cinco oócitos foram reconstruídos pela técnica de TFM e fertilizados com sucesso, quatro se desenvolveram para blastocisto, mas apenas um apresentou cariótipo normal e foi transferido para a paciente, resultando no nascimento de um menino com menos de $6 \%$ de heteroplasmia 4 .

Segundo Zhang, ele e sua equipe foram ao México para realizar o procedimento porque, no México, as técnicas de substituição mitocondrial não são regulamentados nem proibidos especificamente ${ }^{26}$. A paciente atendida pela equipe era portadora assintomática de uma mutação mitocondrial que causava síndrome de Leigh, e apesar de não ter a síndrome, a doença poderia ser transmitida aos seus filhos. De fato, a paciente já havia sofrido quatro abortos espontâneos e havia perdido dois filhos com a doença, que morreram com idades de seis anos e oito meses. A criança nascida a partir da aplicação da técnica, foi saudável aos três meses, embora não se saiba se alguma anormalidade poderá aparecer no futuro ${ }^{14}$. Após a repercussão mundial do Three-parent baby, não foram mais veiculadas notícias sobre a saúde da criança e nenhum artigo foi publicado com o acompanhamento do desenvolvimento do bebê.

\section{CONCLUSÃO}

Mulheres portadores de mutações causadoras da SL podem vivenciar experiências muito tristes ao tentarem realizar o sonho da maternidade. Abortamentos de repetição e filhos que nascem com a doença, desenvolvem sintomas graves relacionados à neurodegeneração e morrem em decorrência da SL são a realidade de muitas delas. Em alguns casos, a SL pode afetar múltiplos membros da família com consequências catastróficas e danos irreparáveis e, devido à falta dos tratamentos disponíveis, a prevenção é a única opção para o controle de herança. As técnicas para substituir mtDNA mutado com mtDNA saudável oferecem às mulheres com mutação no mtDNA a possibilidade de ter uma criança geneticamente relacionada sem o risco de transmissão de doença.

O desenvolvimento e a aplicação clínica de terapias de linha germinal para doenças de mtDNA já são uma realidade. As técnicas vêm sendo aprimoradas para tentar limitar o carregamento do mtDNA mutante, tanto quanto seja praticamente possível. Demonstrou-se que é tecnicamente possível transmitir mtDNA materno $<3 \%$ com TFM e com TPN em embriões humanos pré-implantação ${ }^{28,30}$. Os estudos indicam que com níveis tão baixos de transferência de mtDNA mutante é altamente improvável que qualquer descendente materno venha a desenvolver a SL e que é bastante provável que se possa erradicar a doença para sempre ${ }^{15}$. No entanto, com apenas um caso relatado de nascido vivo após a técnica em seres humanos, é cedo para que conclusões sejam estabelecidas sobre a eficácia da técnica para prevenir a SL.

Apesar dos resultados com relatos positivos sobre a manipulação dos oócitos e embriões in vitro, ainda há dúvidas sobre qual deve ser o melhor método para minimizar a transferência de mtDNA materno durante o procedimento. Além disso, não se sabe se podem ou não existir consequências no funcionamento das mitocôndrias pelo fato de o nDNA ser originado da mãe e o mtDNA ser de uma doadora. Portanto, para que a técnica de substituição mitocondrial, seja ela por TPN ou TFM, seja considerada segura para a aplicação em seres humanos, mais estudos devem ser realizados. Enquanto isso, as mulheres com SL que desejam ser mães com segurança devem recorrer aos meios comprovadamente seguros como a adoção de oócitos ou embriões saudáveis.

\section{Financiamento}

Os autores declaram que não obtiveram auxílio de nenhuma fonte de financiamento.

\section{Conflitos de Interesse}

Os autores declaram não possuírem conflitos de interesse na publicação desse manuscrito.

\section{REFERÊNCIAS}

1. Cree LM, Samuels DC, Chinnery PF. The inheritance of pathogenic mitochondrial DNA mutations. Biochim Biophys Acta. 2009;1792(12):1097-102.

2. Richardson J, Irving L, Hyslop LA, Choudhary M, Murdoch A, Turnbull $\mathrm{DM}$, et al. Concise reviews: assisted reproductive technologies to prevent transmission of mitochondrial DNA disease. Stem Cells. 2015;33(3):639-45.

3. Baertling F, Rodenburg RJ, Schaper J, Smeitink JA, Koopman WJH, Mayatepek E, et al. A guide to diagnosis and treatment of Leigh syndrome. J Neurol Neurosurg Psychiatry. 2014;85(3):257-65.
4. Zhang J, Liu H, Luo S, Lu Z, ChávezBadiola A, Liu Z, et al. Live birth derived from oocyte spindle transfer to prevent mitochondrial disease. Reprod Biomed Online. 2017;34(4):361-8.

5. van der Giezen M, Tovar J. Degenerate mitochondria. EMBO Rep. 2005;6(6):525-30. 
6. Hyslop LA, Blakeley P, Craven L, Richardson J, Fogarty NME, Fragouli E, et al. Towards clinical application of pronuclear transfer to prevent mitochondrial DNA disease. Nature. 2016;534(7607):383-6.

7. Wallace DC, Chalkia D. Mitochondrial DNA genetics and the heteroplasmy conundrum in evolution and disease. Cold Spring Harb Perspect Biol. 2013;5(11):1-47.

8. Bianco B, Montagna E. The advances and new technologies for the study of mitochondrial diseases. Einstein. 2016;14(2):291-3.

9. Zhang J, Liu H, Luo S, ChávezBadiola A, Liu Z, Yang M, et al. First live birth using human oocytes reconstituted by spindle nuclear transfer for mitochondrial DNA mutation causing Leigh syndrome. Fertil Steril. 2016;106(3):E375-6.

10. Farnezi HCM, Goulart ACX, dos Santos A, Ramos MG, Penna MLF. Three-parent babies: mitochondrial replacement therapies. JBRA Reprod Assist. 2020;24(2):189-96.

11. Björkholm $P$, Harish $A$, Hagström E, Ernst AM, Andersson SGE. Mitochondrial genomes are retained by selective constraints on protein targeting. Proc Natl Acad Sci U S A. 2015;112(33):10154-61.

12. Schon EA, DiMauro $S$, Hirano $M$. Human mitochondrial DNA: roles of inherited and somatic mutations. Nat Rev Genet. 2012;13(12):878-90.

13. Uhlén $M$, Fagerberg $L$, Hallström BM, Lindskog C, Oksvold P, Mardinoglu A, et al. Tissue-based map of the human proteome. Science. 2015;347(6220):1-9.
14. Gómez-Tatay L, Hernández-Andreu J, Aznar J. Mitochondrial modification techniques and ethical issues. $J$ Clin Med. 2017;6(3):1-16.

15. Samuels DC, Wonnapinij $P$, Chinnery PF. Preventing the transmission of pathogenic mitochondrial DNA mutations: Can we achieve long-term benefits from germ-line gene transfer? Hum Reprod. 2013;28(3):554-9.

16. Mishra P, Chan DC. Mitochondrial dynamics and inheritance during cell division, development and disease. Nat Rev Mol Cell Biol. 2014;15(10):634-46.

17. DiMauro S, Schon EA. Mitochondrial respiratory-chain diseases. $N$ Engl J Med. 2003;348(26):2656-68.

18. Lake NJ, Compton AG, Rahman S, Thorburn DR. Leigh syndrome: one disorder, more than 75 monogenic causes. Ann Neurol. 2016;79(2):190-203.

19. Lake NJ, Bird MJ, Isohanni P, Paetau A. Leigh syndrome: neuropathology and pathogenesis. $J$ Neuropathol Exp Neurol. 2015;74(6):482-92.

20. Ruhoy IS, Saneto RP. The genetics of leigh syndrome and its implications for clinical practice and risk management. Appl Clin Genet. 2014;7:221-34.

21. Rahman J, Noronha A, Thiele I, Rahman S. Leigh map: A novel computational diagnostic resource for mitochondrial disease. Ann Neurol. 2017;81(1):9-16.

22. Wei Y, Cui L, Peng B. Mitochondrial DNA mutations in late-onset Leigh syndrome. J Neurol. 2018;265(10):2388-95.

23. Chen L, Cui Y, Jiang D, Ma CY, Tse HF, Hwu WL, et al. Management of Leigh syndrome: current status and new insights. Clin Genet. 2018;93(6):1131-40.
24. Sofou $K$, De Coo IFM, Isohanni $P$, Ostergaard E, Naess K, De Meirleir $L$, et al. A multicenter study on Leigh syndrome : disease course and predictors of survival. Orphanet J Rare Dis. 2014;9:52-1-16.

25. Mitalipov S, Amato P, Parry S, Falk MJ. Limitations of preimplantation genetic diagnosis for mitochondrial DNA diseases. Cell Rep. 2014;7(4):935-7.

26. Palacios-González C, Medina-Arellano MJ. Mitochondrial replacement techniques and Mexico's rule of law: on the legality of the first maternal spindle transfer case. J Law Biosci. 2017;4(1):50-69.

27. Wolf DP, Mitalipov N, Mitalipov S. Mitochondrial replacement therapy in reproductive medicine. Trends $\mathrm{Mol}$ Med. 2015;21(2):68-76.

28. Craven L, Tuppen HA, Greggains GD, Harbottle SJ, Murphy JL, Cree LM, et al. Pronuclear transfer in human embryos to prevent transmission of mitochondrial DNA disease. Nature. 2010;465(7294):82-5.

29. Wolf DP, Hayama T, Mitalipov S. Mitochondrial genome inheritance and replacement in the human germline. EMBO J. 2017;36(15):2177-81.

30. Tachibana M, Amato $\mathrm{P}$, Sparman M, Woodward J, Sanchis DM, Ma H, et al. Towards germline gene therapy of inherited mitochondrial diseases. Nature. 2013;493(7434):627-31.

31. Kang E, Wu J, Gutierrez NM, Koski A, Tippner-Hedges R, Agaronyan K, et al. Mitochondrial replacement in human oocytes carrying pathogenic mitochondrial DNA mutations. Nature. 2016;540(7623):270-5.

Recebido: 09 jul, 2020 Aceito: 29 out, 2020 